\title{
An image-based method to determine the particle size distribution (PSD) of fine-grained soil
}

The Mining-Geology-Petroleum Engineering Bulletin UDC: 551.24 (author's propose) DOI: $10.17794 / \operatorname{rgn} .2019 \cdot 3.9$

Preliminary communication

\author{
Saman Tabrizi-Zarringhabaei'; Reza Goli Ejlalii ${ }^{*}$; \\ Mikaeil Yousefzadeh Fard'; Sayyedjavad Sayyedfattahi ${ }^{2}$ \\ ${ }^{1}$ Department of Civil Engineering, Tabriz Branch, Islamic Azad University, Tabriz, Iran \\ ${ }^{2}$ Department of Electrical Engineering, Tabriz Branch, Islamic Azad University, Tabriz, Iran
}

\begin{abstract}
This paper discusses the PSD effects on the behavior of soil and its properties. The coarse grain part of soil can be analyzed with sieve analysis. Evaluating the PSD of fine-grained soil with the traditional method (hydrometer analysis) is a time-consuming process, has laboratory complexities and the obtained results are not accurate. Due to these limitations, there is a demand for a method that can offer faster data with more accuracy for geotechnical engineering. In this paper, the digital image processing (DIP) method is proposed using microscopic images and MATLAB software to determine the PSD of fine-grained soil. The DIP method was compared with the hydrometer analysis. The analysis of the data obtained from these two methods indicated that the image based method is capable of providing faster and more comprehensive results of the PSD.
\end{abstract}

\section{Keywords:}

image processing, fine-grained soil, hydrometer analysis, MATLLAB software

\section{Introduction}

One of the most useful pieces of data about soil is regarding the size of its particles. The PSD is an important part of soil mechanics, especially geotechnical engineering. The PSD of soil is utilized for soil classification and consequently, it can be applied in the forecasting of every mechanical and hydrologic soil behavior containing the specific weight, cohesion, permeability, etc. The common method for determining PSD includes sieve analysis (ASTM D6913, 2017) and hydrometer analysis (ASTM D7928, 2017). Hydrometer analysis is based on the principle of sedimentation and Stoke's law so it has some limitations and it is a time-consuming process (Coates and Hulse, 2012). The field of DIP is continuously developing and is used in many sciences. For example, digital image processing is used in criminology for fingerprint matching, automatically interpreting fingerprints for dermatoglyphic applications (Mardia et al., 1997). Image processing plays an important role in many medical treatments, for example, magnetic resonance imaging and digital mammography are an important sector of diagnoses (Pham et al., 2000). Based on computer vision, cell injection is experimentally done with 100\% successful results (Wang et al., 2009). Identifying individuals by an image of a biometric character-

Corresponding author: Reza Goli Ejlali

Reza_ejlali@iaut.ac.ir istic such as their signature (Jain et al., 2006). Evaluating the quality of drugs, food and metal production by image analysis techniques (Du and Sun, 2004; Eremin, 2006; Islam et al., 2008).

Classification of soils through the DIP method has the benefits of reducing the number of operators, decreasing calculation errors, offering stable image-based data of a sample, and it is faster than the traditional method (hydrometer analysis). Many researchers have used image analysis to find engineering properties.

Mahmoud et al., (2010) presented a new numerical method that mixes the discrete element method (DEM) and the DIP method for studying the mixed effects of grain properties on hot-mix asphalt (HMA). Tafesse et al., (2012) developed a novel image-based method for calculating the 3-D shape and size of soil particles. A Glow-In-the-Dark (GID) method was used to produce a bright background and images were analyzed with MATLAB software. Sochan et al., (2015) used images of sand particles to determine the shape parameters and compared the results with the Krumbein technique. Kuo et al., (1996) developed a 3-D image-based analysis of gravel that was carried out with adding gravel in trays that can keep the grain and rotate it ninety degrees for quality control of gravel utilized in HMA. Kuo, (2002) carried out a mathematical analysis for determining the relevance between the permanent deformation properties of HMA and its particle geometric irregularities. The 
image-based method has a significant role in appraising HMA particles for engineering analysis. Rao and Tutumluer, (2000) used a novel imaging technique to determine the volume, shape, and angularity of coarse grain used in asphalt pavement. Sukumaran and Ashmawy, (2001) determined grain morphology by formulating two new parameters. Parameters can be used as quality control of material selection for civil engineering. Bowman et al., (2001) developed a quantitative method using Fourier shape descriptors and image analysis for sand particle shape characterization. Fletcher et al., (2003) designed a unified computer-automated system for characterizing the shape of particles. Wilson et al., (1996) presented a novel video-based technique for quantifying the angularity of sand particles used in asphalt concrete based on the properties of the mathematical tool. White, (2003) developed a modern method for determining the PSD of sand by using an optical sensor and compared it with the traditional method. Wettimuny et al., (2004) investigated Shape analysis of coarse aggregate particles using Fourier transforms of digital images. Fourier transforms are used to assess its spectral information. Wen et al., (2002) used the traditional method and a laser-based method for analyzing particle size and compared both methods.

A lot of studies on image-based particles size have been conducted as mentioned above. However, none of them have focused on fine-grained soil. The purpose of this paper is to describe a rapid technique called DIP to determine the fine-grained PSD of samples.

\section{Material and methods}

Image processing is a type of signal processing where the input is an image, such as a picture or a scene of a movie, and the output can either be an image, or a set of special characters or image variables. DIP is performed by computers and image processing software. DIP for analyzing the morphological characteristics of materials, especially materials used in civil engineering, includes the following steps: a) take images; b) image segmentation and thresholding; c) image processing and extraction of particle-specific characteristics; d) computing and expanding this information by parameters and functions.

In DIP, the last two steps are performed by software. There are currently various image processing programs, of which MATLAB software was selected for this paper. The input image to the software to extract the features must first be calibrated. Calibrating the image means that the actual size of the image should be introduced to the computer. This is usually done by specifying a calibrated number based on the scale of the image and its magnification. A calibrated number is a pixel size per unit micrometer, which plays a very important role in computing. In the following steps, with the help of the separation tool, the useful phases in the image are separated. There are

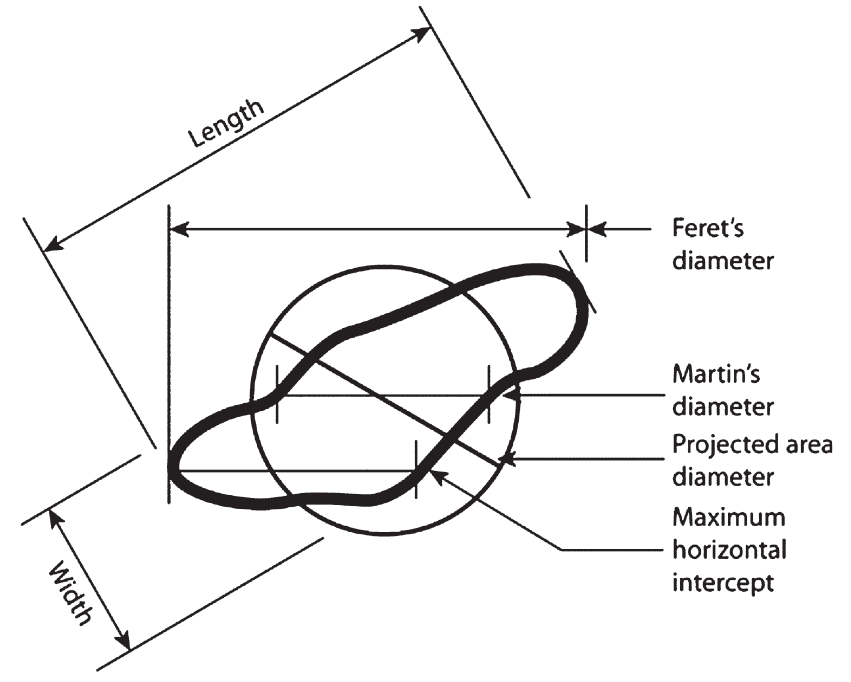

Figure 1: Common definitions for particle size in microscopic method (Rawle, 2010)

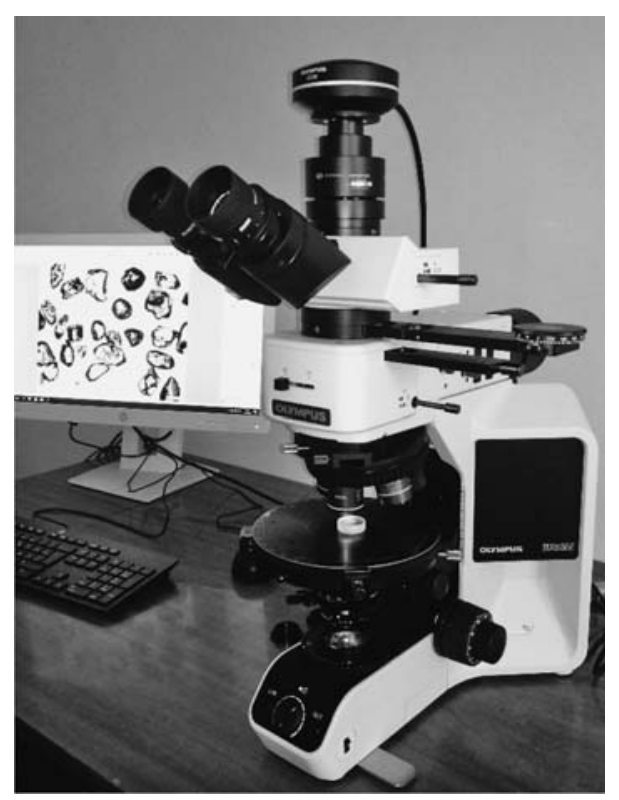

Figure 2: Digital image processing hardware

several methods for separation in image processing science, but in this paper, the threshold method based on the histogram of the image was used. Finally, the features obtained from the image provide the required information with the help of the functions provided in the software. Depending on the size of the material, digital cameras can be used directly or connected to a microscope to provide the image. The computer makes calculations according to the pixels of the image, and, if using a high-quality image, the results will be precise.

In general, there is no definite definition for particle size. Particles of soil and rock are three-dimensional and have an irregular shape. Particle measurement varies depending on the shape of the particles. For spherical particles, the size is defined by diameter. For irregular particles, there are various definitions that particle size 


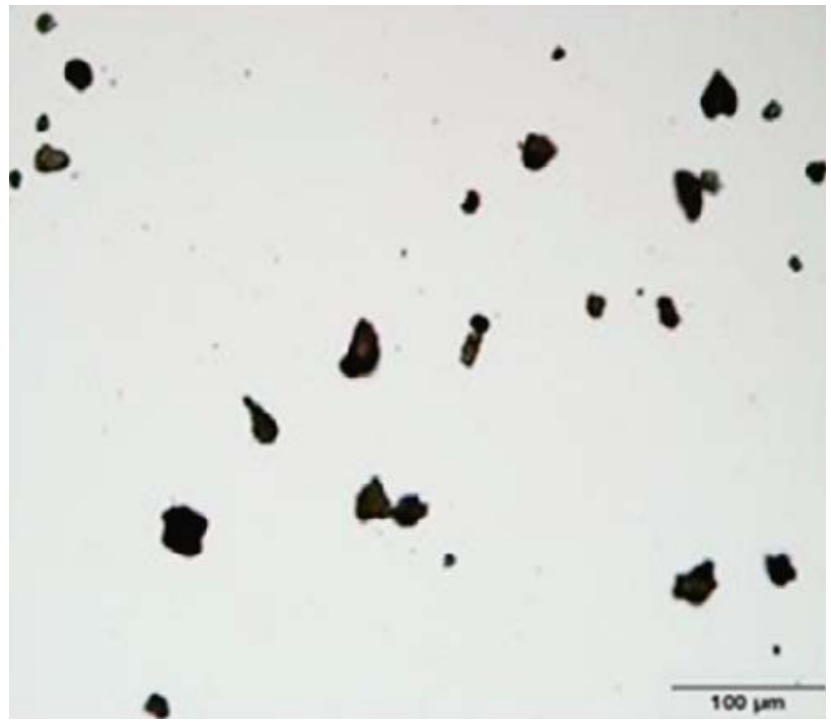

Figure 3: Image recorded from fine-grained soil by optical microscope characteristics should include information on the type of measured diameter and also the shape of the particles. Some common definitions for determining the particle size used in microscopic observations are shown in Figure 1.

The microscopic images were prepared by an Olympus optical microscope BX53M attached to a computer system and a DP72 digital camera. The computer system is used to control the input for the MATLAB software and to show the output results. All these components are shown in Figure 2.

\subsection{Calculation}

In this study, after preparing fine-grained samples, the images were prepared for image analysis. An example of a microscopic image of soil particles is shown in Figure 3.

Using a simple analysis, the changes in particle size parameters were monitored by increasing the number of

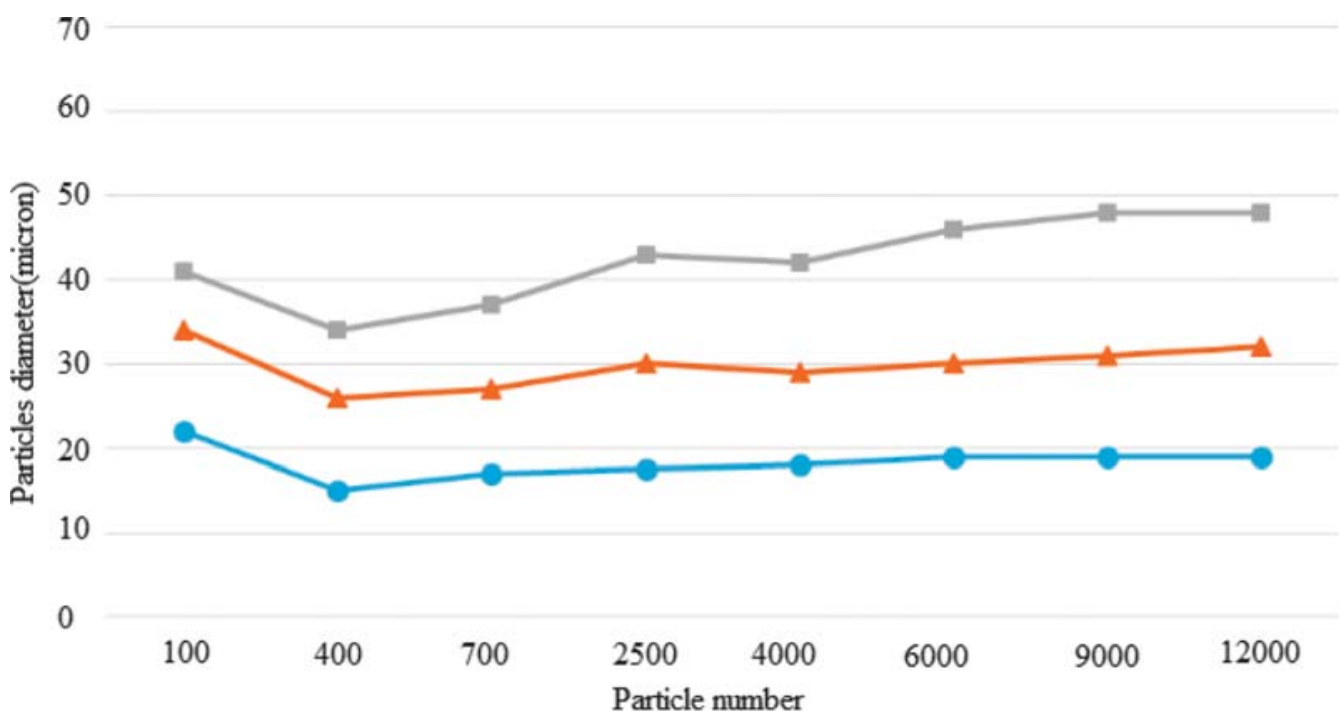

$\rightarrow \mathrm{d}_{10}$ : Diameter of the soil particles for which 10 percent of the particles are finer

$-\mathrm{d} 50$ : Diameter of the soil particles for which 50 percent of the particles are finer

$-{ }_{-1}$ d9: Diameter of the soil particles for which 90 percent of the particles are finer

Figure 4: Effect of number of particles on PSD by DIP

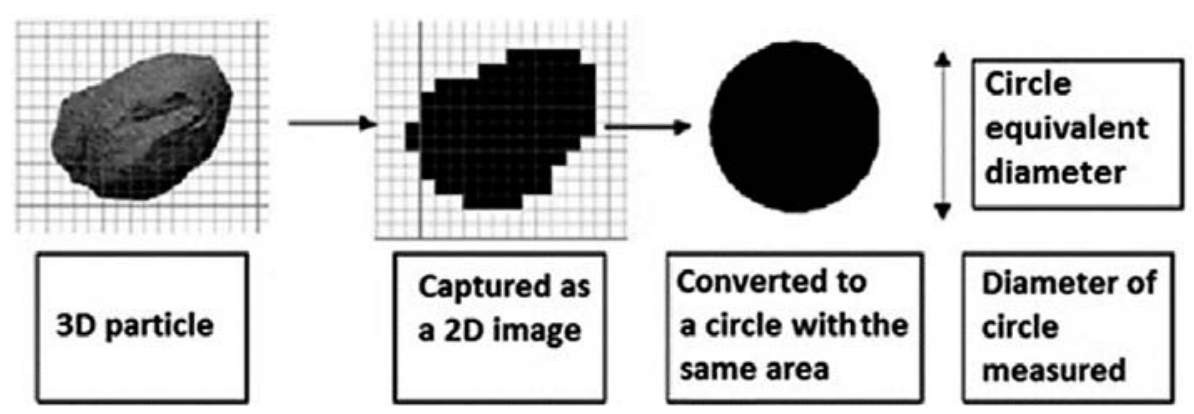

Figure 5: Determine the particle diameter in the image processing method (Willen, 2008) 
analyzed particles. The results of this analysis are shown in Figure 4. As shown in Figure 4, between 9000 and 12000 particles, the results are linear, and therefore, in this study, 12000 fine-grained particles were tested. To achieve more accurate results, soil particles should be well dispersed with appropriate methods. In this study, the sample was spread on a dry and flat surface and a micro tweezer was used to disperse it. However, the sample preparation for fine-grained particles is difficult.

After providing the images by the camera attached to the optical microscope, the final step is to analyze the images with the software. The particle size in this method is expressed in terms of the diameter of the circle equivalent to the area of the two-dimensional image of the particle as shown in Figure 5.

Using microscopic image processing, particles can be measured in the range of one millimeter to one micrometer. It is notable that the hydrometer analysis is based on grain weight, and the raw data obtained from the image analysis is based on the number of grains. In order to compare the results of the two methods, the data obtained from the microscopic image analysis in terms of the number were converted to in terms of volume.

DIP makes a precise calculation of the area $\left(\mathrm{A}_{\mathrm{i}}\right)$ possible by determining the number of pixels involved in the grains. This kind of investigation is an advancement over manual techniques. By the parameter $t_{i}$, the $A_{i}$ is converted to volume $\left(\mathrm{V}_{\mathrm{i}}\right)$ for grain $i$. The parameter $t_{i}$ is defined as Equation 1.

$$
t_{i}=\frac{V_{i}}{A_{i}}
$$

The parameter $t_{i}$ shows the thickness of grains that cannot be specified by 2D microscopical calculations. In any case, it is accepted that $t_{i}$ will obey based on two assumptions.

Assumption one is that $t_{i}$ is constant and shows an identical third dimension for all grains. This situation shows the volume weighted distribution of flat plates. In this situation, the $V_{i}$ distributions histogram of grains are independent of $t_{i}$. The fraction of grains in the size range $11 \leq \mathrm{S}_{\mathrm{i}} \leq 12$ over $n$ entire grains is defined as Equation 2:

$$
\frac{\sum_{\mathrm{Si}=11}^{12} \mathrm{~V}_{\mathrm{i}}}{\sum_{\mathrm{i}=1}^{\mathrm{n}} \mathrm{V}_{\mathrm{i}}}=\frac{\mathrm{t}_{\mathrm{i}} \sum_{\mathrm{Si}=11}^{12} \mathrm{~A}_{\mathrm{i}}}{\mathrm{t}_{\mathrm{i}} \sum_{\mathrm{i}=1}^{\mathrm{n}} \mathrm{A}_{\mathrm{i}}}
$$

In assumption one, the $\mathrm{A}_{\mathrm{i}}$-weighted and $\mathrm{V}_{\mathrm{i}}$-weighted distributions are the same.

Assumption two is that the $t_{i}$ increases at the same rate as the other dimensions. This situation shows the $\mathrm{V}_{\mathrm{i}}-$ weighted distribution of globular grains. Here, $t_{i}$ is given by Equation 3.

$$
\mathrm{t}_{\mathrm{i}}=\mathrm{K}\left(\mathrm{A}_{\mathrm{i}}\right)^{0.5}
$$

Where $\mathrm{K}$ is a fixed coefficient. Equation (1) and (3) are combined and yields Equation 4.

$$
\mathrm{V}_{\mathrm{i}}=\mathrm{K}\left(\mathrm{A}_{\mathrm{i}}\right)^{1.5}
$$

The $\mathrm{K}$ is a shape-based coefficient. For example, for globular grains, $\mathrm{K}$ is given by Equation 5.

$$
\mathrm{K}=4 / 3 \frac{1}{\pi^{0.5}}
$$

The shape of a distributed histogram based on the $\mathrm{V}_{\mathrm{i}}$ of grains is independent of the $\mathrm{K}$. The fraction of grains in the size range $11 \leq S_{i} \leq 12$, over $n$ entire grains is given by Equation 6.

$$
\frac{\sum_{\mathrm{S}=11}^{12} \mathrm{~V}_{\mathrm{i}}}{\sum_{\mathrm{i}=1}^{\mathrm{n}} \mathrm{V}_{\mathrm{i}}}=\frac{\mathrm{K} \sum_{\mathrm{Si=11}}^{12}\left(\mathrm{~A}_{\mathrm{i}}\right)^{1.5}}{\mathrm{~K} \sum_{\mathrm{i}=1}^{\mathrm{n}}\left(\mathrm{A}_{\mathrm{i}}\right)^{1.5}}
$$

\subsection{Method validation}

For validating the accuracy of the DIP method, a set of measurements of standard particles (Sigma-Aldrich) have been carried out. The average diameter of this product has been calibrated with the SIGMA-ALDRICH corporation. The average size and other properties of the certified particles are given by the corporation and listed in Table 1. By utilizing the DIP method, the certified

Table 1: Properties of the certified particles (Sigma-Aldrich)

\begin{tabular}{|l|l|}
\hline \multicolumn{2}{|c|}{ Product attributes } \\
\hline Particle composition & Aluminum oxide \\
\hline Particle density & $4.0 \mathrm{~g} / \mathrm{cm}^{3}$ \\
\hline Average particles size & 10 micron \\
\hline
\end{tabular}

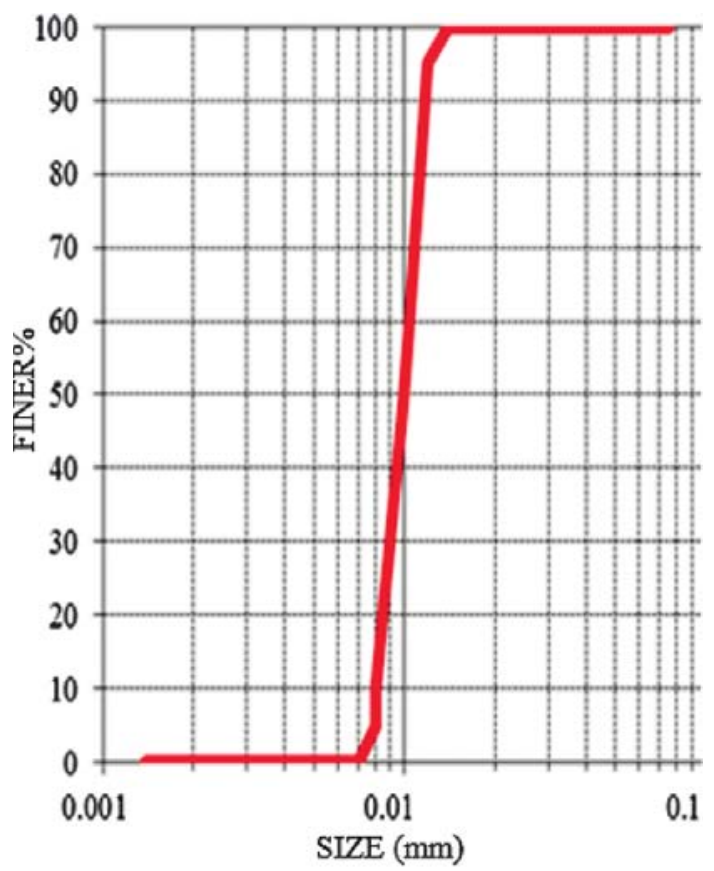

Figure 6: Particle size distribution of aluminum oxide by DIP 
particles are measured to specify the PSD is shown in Figure 6. The result is compared to the data provided by the corporation. It obviously shows that the measured

Table 2: Soil description

\begin{tabular}{|l|l|l|l|l|}
\hline $\begin{array}{l}\text { Soil } \\
\text { number }\end{array}$ & Soil color & $\begin{array}{l}\text { Color } \\
\text { uniformity }\end{array}$ & $\begin{array}{l}\text { plasticity } \\
\text { index }\end{array}$ & $\begin{array}{l}\text { Soil } \\
\text { name }\end{array}$ \\
\hline 1 & Brown & Uniform & 36 & CH \\
\hline 2 & Yellow & Uniform & 11 & CL \\
\hline 3 & Olive & Uniform & 47 & CH \\
\hline 4 & Grey & Uniform & 3 & ML \\
\hline
\end{tabular}

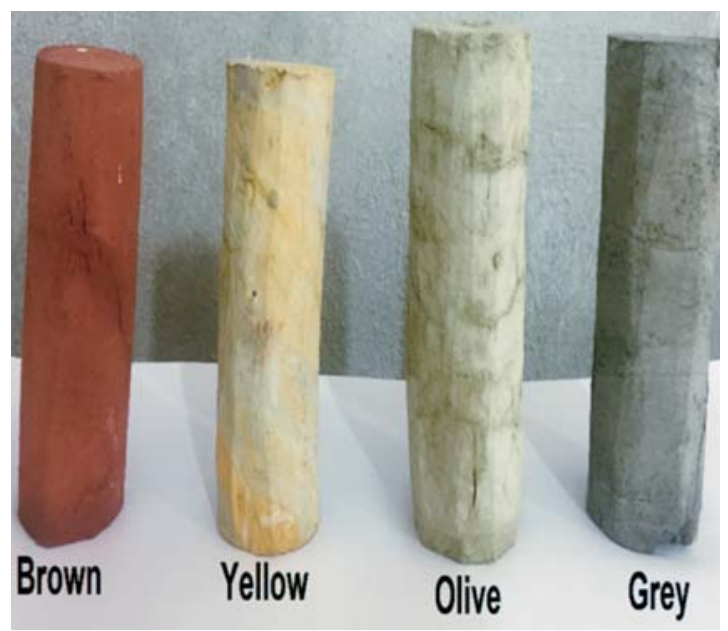

Figure 7: Soil samples
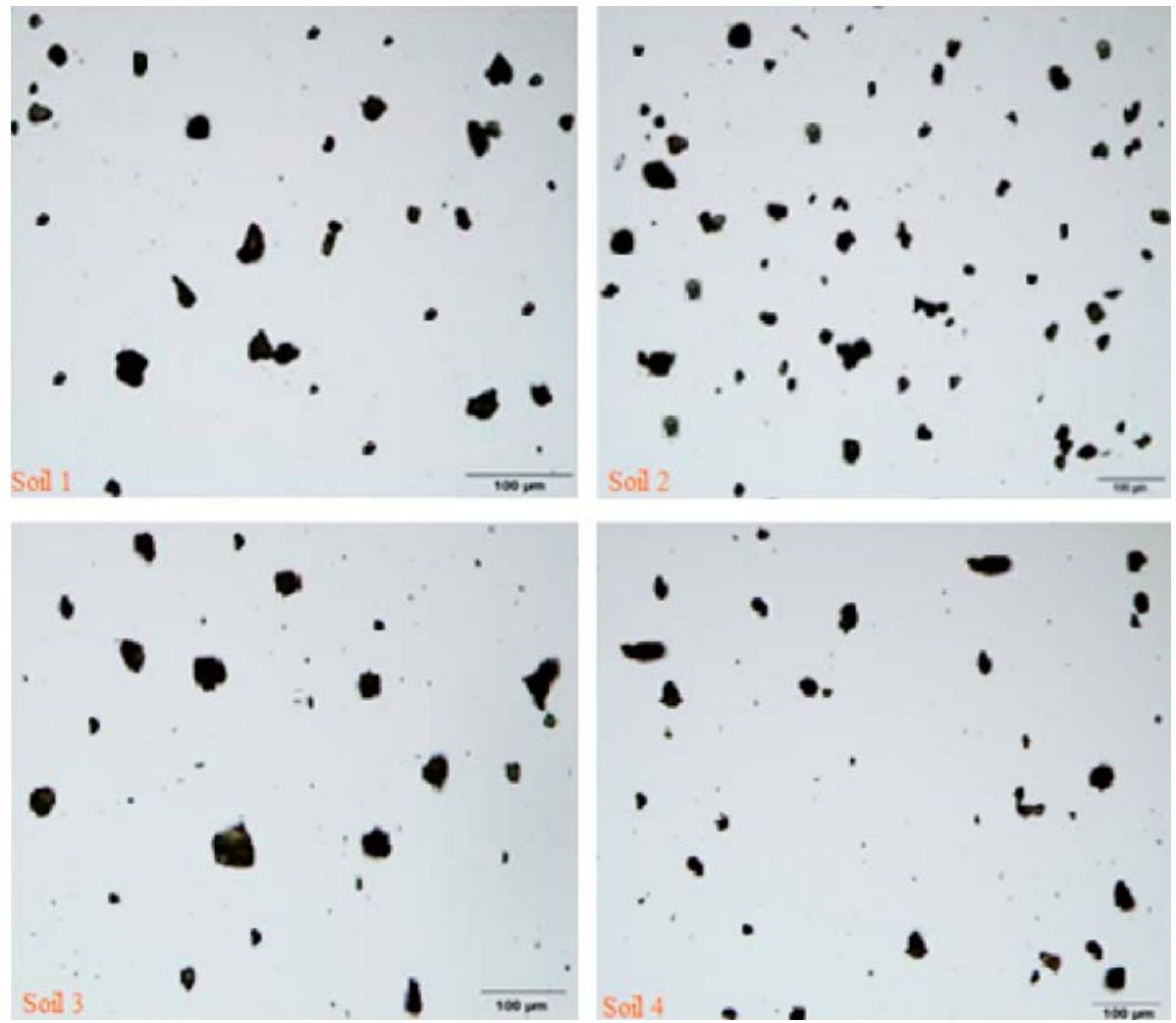

Figure 8: Soil sample microscopic images result is in good agreement with the data provided by the corporation so it can be concluded that the imaging instrument is accurate and reliable in sizing particles.

\subsection{Soil sample}

Tests were carried out on four various samples for comparing the DIP method and the hydrometer analysis. The soil properties were specified and are mentioned in Table 2. Soil samples are shown in Figure 7. These samples are the most frequent soil type in Tabriz city. The (ASTM D2487, 2010) standard is used to determine the soil classification. The samples microscopic images are shown in Figure 8.

\section{Results and Discussions}

Due to the type of application of PSD in civil engineering, the results should be in terms of the percentage of particle passing weight. In the image analysis method, a small amount of the sample is tested so that it cannot be easily weighed. Assuming that the particle density is constant, according to the equations described earlier, particle volumes are determined using their area. Curves based on the number of particles are converted into the curves based on the area and volume. Now it is possible to compare DIP and hydrometer analysis. The results of the DIP were compared to hydrometer analysis as shown in Figures 9, 10, 11, and 12. The hydrometer analysis 


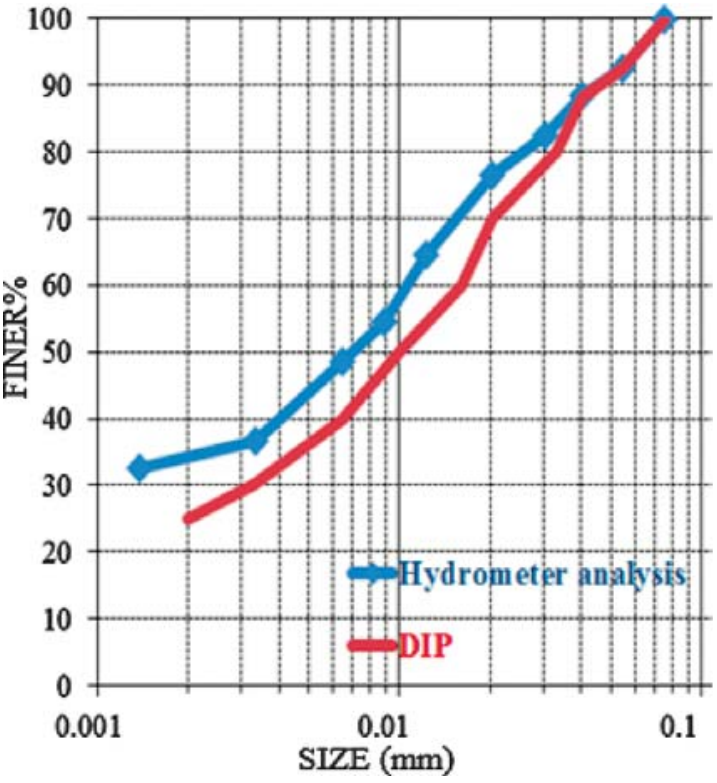

Figure 9: Particle size distribution curve: soil number 1

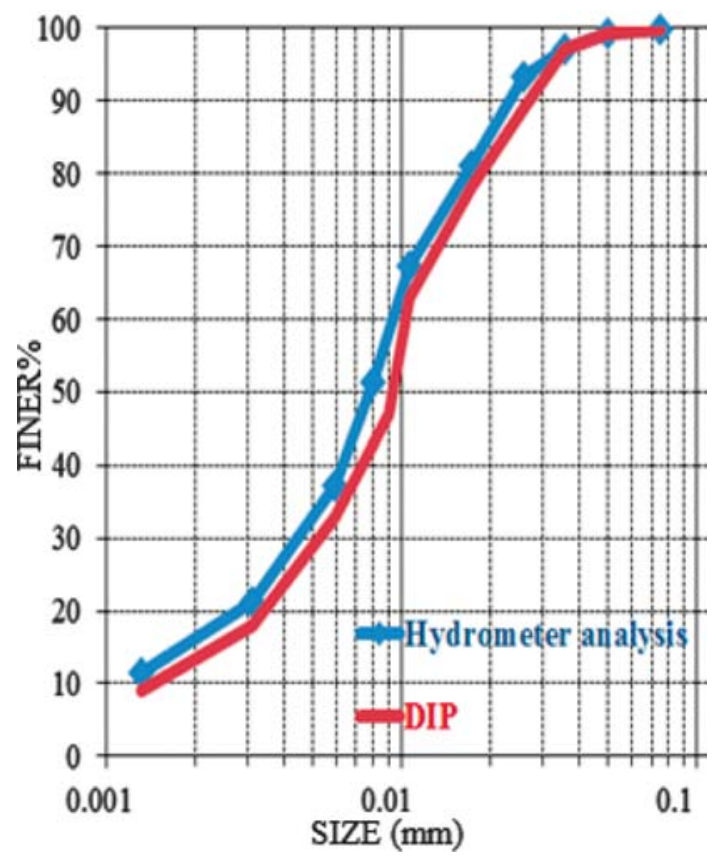

Figure 10: Particle size distribution curve: soil number 2

was carried out in a ZAMIN-AZHAND-KAV laboratory.

The discrepancies in view of the two data categories are because of the reality that the hydrometer analysis creates only 11 data points compared to the many data points received through the DIP method. So, in spite of some differences, assent was noticeable between the DIP method and hydrometer analysis results. The difference between the graphs is due to the lack of data regarding the thickness of the particles. The results showed that particles larger than 40 microns have a more regular

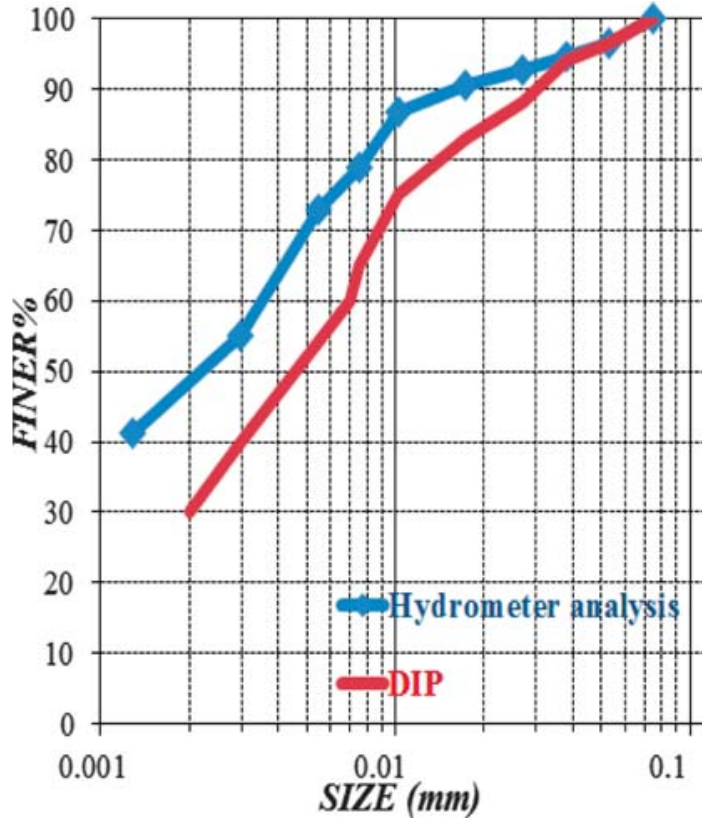

Figure 11: Particle size distribution curve: soil number 3

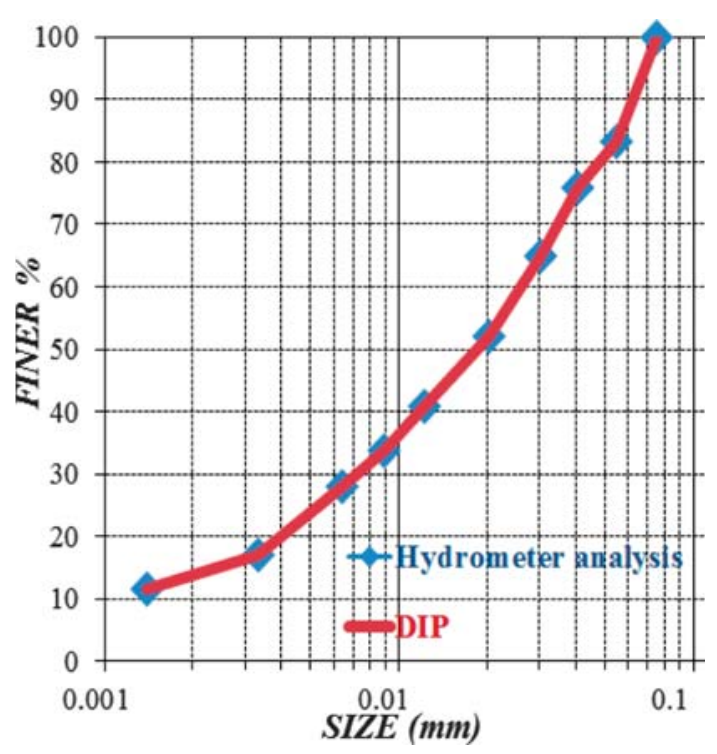

Figure 12: Particle size distribution curve: soil number 4

shape pattern than smaller particles and are closer to a full sphere shape.

According to Figure 11, excellent similarity was seen between the DIP method and hydrometer analysis results in silt soil because silt particles are bigger than clay particles and particles are spherical.

The results showed that the DIP method could be used for all type of fine-grained soil and it is more trustworthy than hydrometer analysis.

\section{Conclusions}

The PSD analysis using an image processing technique was studied in this paper. The particle size for 
comparative results of the hydrometer analysis and DIP method were calculated from two-dimensional images of particles. There is almost complete overlapping between the DIP method and the hydrometer analysis results. Compared to the hydrometer analysis, the DIP method is much more trustworthy as it omits human error and could be performed without the need for special skills and experience. Also, the DIP method is fast and simple. In fact, from the image of soil, particle shapes can also be analyzed. The DIP method can replace common laboratory methods.

\section{References}

ASTM D6913 / D6913M-17 (2017): Standard Test Methods for Particle-Size Distribution (Gradation) of Soils Using Sieve Analysis, ASTM International, West Conshohocken, PA.

ASTM D7928-17 (2017): Standard Test Method for ParticleSize Distribution (Gradation) of Fine-Grained Soils Using the Sedimentation (Hydrometer) Analysis, ASTM International, West Conshohocken, PA.

ASTM D2487-17 (2017): Standard Practice for Classification of Soils for Engineering Purposes (Unified Soil Classification System), ASTM International, West Conshohocken, PA.

Bowman, E.T., Soga, K. and Drummond, W. (2001): Particle shape characte- risation using fourier descriptor analysis. Geotechnique, 51, 6, 545-554.

Coates, G.F. and Hulse, C.A. (2012): A comparison of four methods of size analysis of fine-grained sediments. New Zealand Journal of Geology and Geophysics, 28, 2, 369-380.

Du, C.J. and Sun, D.W. (2004): Recent developments in the applications of image processing techniques for food quality evaluation. Trends in Food Science \& Technology, 15, $5,230-249$.

Eremin, S.N. (2006): Image processing technology in the systems for quality control of sheet metal roll. Pattern Recognition and Image Analysis, 16, 1, 127-130.

Fletcher, T., Chandan, C., Masad, E. and Sivakumar, K. (2003): Aggregate imaging system for characterizing the shape of fine and coarse aggregates. Transportation Research Record: Journal of the Transportation Research Board, 1832, 1, 67-77.

Islam, M.J., Ahmad, M.i and Sid-Ahmed, M.A. (2008): Image processing techniques for quality inspection of gelatin capsules in pharmaceutical applications. 10th International Conference on Control, Automation, Robotics and Vision, Vietnam, 862-867.

Jain, A.K., Ross, A. and Pankanti, S. (2006): Biometrics: A tool for information security. IEEE Transactions on Information Forensics and Security, 1, 2, 125-143.

Kuo, C.Y., Frost, J.D., Lai, J.S. and Wang, L.B. (1996): Threedimensional image analysis of aggregate particles from orthogonal projections. Transportation Research Record: Journal of the Transportation Research Board, 1526, 1, 98-103.
Kuo, C. (2002): Correlating permanent deformation characteristics of hot-mix asphalt with aggregate geometric irregularities. Journal of Testing and Evaluation, 30, 2, 136-144.

Mahmoud, E., Masad, E. and Nazarian, S. (2010): Discrete element analysis of the influences of aggregate properties and internal structure on fracture in asphalt mixtures. Journal of Materials in Civil Engineering, 22, 1, 10-20.

Mardia, K.V., Baczkowski, A.J., Feng, X. and Hainsworth, T.J. (1997): Statistical methods for automatic interpretation of digitally scanned-finger prints. Pattern Recognition Letters, 18, 11-13, 1197-1203.

Pham, D.L., Xu, C. and Prince, J.L. (2000): Current methods in medical image segmentation. Annual Review of Biomedical Engineering, 2, 315-337.

Rao, C. and Tutumluer, E. (2000): Determination of volume of aggregates: new image-analysis approach. Transportation Research Record: Journal of the Transportation Research Board, 1721, 1, 73-80.

Rawle, A.F. (2010): Analytical Tools for Suspension Characterization. In: Kulshreshtha, A., Singh, O. and Wall, G. (eds.): Pharmaceutical Suspensions.- Springer, New York, NY, 177-230.

Sochan, A., Zielińsk, P. and Bieganowski A. (2015): Selection of shape parameters that differentiate sand grains, based on the automatic analysis of two-dimensional images. Sedimentary Geology, 327, 14-20.

Sukumaran, B. and Ashmawy, A.K. (2001): Quantitative characterisation of the geometry of discrete particles. Geotechnique, 51, 7, 619-627.

Tafesse, S., Fernlund, J.M.R. and Bergholm, F. (2012): Digital sieving-Matlab based 3-D image analysis. Engineering Geology, 137-138, 74-84.

Wang, W.H., Liu, X.Y. and Sun Y. (2009): High-throughput automated injection of individual biological cells. IEEE Transactions on Automation Science and Engineering, 6, 2, 209-219.

Wen, B., Aydin, A. and Duzgoren-Aydin, N.S. (2002): A comparative study of particle size analyses by sieve-hydrometer and laser diffraction methods. Geotechnical Testing Journal, 25, 4, 434-442.

Wettimuny, R. and Penumadu, D. (2004): Application of fourier analysis to digital imaging for particle shape analysis. Journal of Computing in Civil Engineering, 18, 1, 2-9.

White D.J. (2003): PSD measurement using the single particle optical sizing (SPOS) method. Geotechnique, 53, 3, 317326.

Willen, Ulf. (2008): Automation in Image Analysis for Particle Size and Shape Measurement. Malvern Instruments.

Wilson, J.D. and Klotz, L.D. (1996): Quantitative analysis of aggregate based on hough transform. Transportation Research Record: Journal of the Transportation Research Board, 1530, 1, 111-115.

\section{Internet source}

URL:https://www.sigmaaldrich.com/catalog/search?term=26 $5497 \&$ interface $=\mathrm{All} \& \mathrm{~N}=0 \&$ mode $=$ match $\% 20$ partialmax \&lang=en\&region $=$ IR \& focus $=$ product 


\section{SAŽETAK}

\section{Metoda digitalne obradbe slika za određivanje raspodjele veličine zrna u sitnozrnatome tlu}

Veličina zrna tla utječe na njegova svojstva. Krupnozrnata frakcija može biti analizirana prosijavanjem. Nasuprot tomu, proučavanje sitnozrnate frakcije tradicionalnom metodom, tj. hidrometarskom analizom, zahtijeva mnogo vremena, složenu laboratorijsku opremu, a ne mora voditi niti do točnih rezultata. Također, postoji mali broj metoda koje mogu ponuditi veću točnost i brzinu. Stoga je ovdje opisana metoda digitalne obradbe slika dobivenih mikroskopom te obrađenih u paketu MATLAB, a s ciljem određivanja veličine zrna u sitnozrantome tlu. Rezultati su uspoređeni s onima dobivenima hidrometarskom analizom. Njihovom usporedbom metoda digitalne obradbe slika brže je dovela do rezultata, koji su ujedno i bolji.

\section{Ključne riječi:}

obradba slika, sitnozrnato tlo, hidrometarska analiza, MATLAB

\section{Authors contribution}

Saman Tabrizi-Zarringhabaei (PhD candidate): provided the images of samples. Reza Goli Ejlali (Assistant Professor) planned the research, initialized the idea, managed the whole process and supervised it from the beginning to the end. Mikaeil Yousefzadeh Fard (Assistant Professor) completed literature review and participated in all work stages such as providing soil samples, running experimental tests and data analysis. Sayyedjavad Sayyedfattahi (Assistant Professor) performed the image processing. 